\title{
Model pile response to multi-amplitude cyclic lateral loading in cohesionless soils
}

\author{
C.N. Abadie \& B.W. Byrne \\ Department of Engineering Science, University of Oxford \\ S. Levy-Paing \\ Département THEMIS, EDF R\&D
}

\begin{abstract}
Monopile foundations for offshore wind turbines are subjected to many cycles of loading during their lifetime. This loading consists of a range of amplitudes, applied in various sequences, of many different cycle numbers. Calculation of the accumulated rotation experienced by the monopile as a result of this cyclic loading, and whether this exceeds allowable limits, is an important part of the design process. This paper provides an overview of recent research exploring laterally loaded pile response relevant to the design of offshore wind turbine monopiles. Experimental equipment for carrying out cyclic lateral loading tests is introduced, along with considerations of scaling for model testing. Results from a series of small scale model tests covering realistic multi-amplitude testing are then presented, providing new insight into the behaviour of rigid piles subjected to cyclic loading. The results are interpreted using a linear superposition method, as typically used for structural fatigue calculations, and this shows a good fit to the experimental results.
\end{abstract}

\section{INTRODUCTION}

Offshore wind turbines are being installed in ever greater numbers around the UK and Europe. The most common foundation design is the large diameter monopile; a single pile upon which the turbine is located. These piles are substantially larger than piles used for oil and gas applications, with diameters up to $10 \mathrm{~m}$ being considered for future designs. Consequently there are concerns about whether current design approaches imported from oil and gas design, particularly for lateral loading, are robust. In addition there is limited guidance for assessing the effects of cyclic loading on pile response, both during storm loading and also over the lifetime of the structure.

To respond to these concerns a number of recent research programs have focused on cyclic loading of piles, principally through laboratory model testing. The aim of these testing programs has been to explore pile response under constant amplitude cyclic loading, and in particular the evolution of the foundation response (e.g. rotation, stiffness) with the number of cycles (e.g. Leblanc et al., 2010a; Peralta, 2010; Klinkvort, 2012; Cuéllar, 2011). It is recognised that the loading on the foundation, caused by the wind and wave environment, is likely to comprise a range of amplitudes rather than a single, or constant, amplitude. Therefore further experimental work is needed to determine the equivalence be- tween multi-amplitude and constant amplitude cyclic loading.

This paper presents experimental results, from model scaled pile tests in sand that explores multiamplitude loading. The experimental equipment is described along with the framework for interpreting both constant amplitude and multi-amplitude test results. The results from a number of constant amplitude cyclic loading tests along with two multiamplitude tests are presented. They are interpreted using currently available methods, and provide a basis against which future work can be developed.

\section{LATERAL LOADING MODEL PILE TESTS}

\subsection{Background and motivation}

Recent research on pile response to cyclic lateral loading (e.g. Leblanc et al. 2010a; Peralta, 2010; Klinkvort, 2012; Cuéllar, 2011; Abadie \& Byrne, 2014) demonstrates that constant amplitude cyclic loading can cause significant increases in pile deflection and rotation over time. This effect is typically described as accumulated displacement with cycle number, and experimental data from such experiments have been fitted using both power and logarithmic laws by a range of Authors.

For example Leblanc et al. (2010a) show that the evolution of the accumulated rotation $\Delta \theta$ for constant amplitude cyclic loading can be described by 
the power law given in Equation (1). In this calculation $\theta_{0}$ and $\theta_{N}$ is the pile rotation at cycle 1 and $N$ respectively, $\theta_{s}$ is the static rotation that would occur under the maximum cyclic load, and $T_{b}$ and $T_{c}$ are dimensionless empirical functions that depend on the load magnitude, load amplitude and soil relative density. The exponent in Equation (1) is empirically determined from the data in Leblanc et al. (2010a).

$$
\frac{\Delta \theta}{\theta_{s}}=\frac{\theta_{N}-\theta_{0}}{\theta_{s}}=T_{b} \cdot T_{c} \cdot N^{0.31}
$$

It is noted that whether power law or logarithmic law descriptions are used both account for the effects of cycle number on pile response, an aspect that is currently missing from current design guidance.

In addition, the authors cited above have studied the influence of parameters related to the pile aspect ratio (embedded length $L$ over diameter $D$ ) and pile relative stiffness (the definition is detailed in section 2.3). Dietrich (1982) and Peralta (2010) demonstrate that these two parameters are very important in determining the pile response to lateral loading.

Over the past decade a number of experimental studies have explored rigid pile response to constant amplitude cyclic loading, leading to expressions such as that described by Equation (1). Real loading on offshore structures is not constant amplitude but consists of a range of loading amplitudes, and is referred to as multi-amplitude cyclic loading. Published work by Leblanc et al. (2010b) and Peralta (2010) investigated the influence of ascending and descending load combinations on pile response, capturing their results using concepts based on Miner's linear cumulative damage rule (Miner, 1945). Both demonstrate that the loading history has an influence on the pile response whilst Leblanc et al. (2010b) found that Miner's rule provided a reasonable approximation for the sequences investigated.

If these two studies are the first steps towards a better understanding of the pile response to multi amplitude cyclic loading, they only involve very limited data sets, with the loading featuring 1,000 cycles per load sequence. As a result, they are not completely representative of offshore loading conditions, and in particular, do not address what the pile response could be during and after a storm period. This paper presents model test results that address this issue, along with a method for predicting the observed pile response.

\subsection{Experimental techniques}

The model experiments described here were conducted using equipment developed by Rovere (2004), and used by Leblanc et al. (2010a, 2010b).
The system consists of a combination of suspended and rotating masses which enforce a lateral cyclic load at a representative height above the soil surface. The motor frequency is $0.106 \mathrm{~Hz}$ corresponding to the peak frequency of offshore waves. As a result, the pile is subjected to a combined lateral force and moment loading at the mud-line with the moment loading defined as the horizontal load at the pile top multiplied by the pile length above soil surface.

Figure 1 shows a schematic of the system. Highquality measurement of the pile deflection is determined using two displacement transducers (LVDTs), from which the pile rotation is also calculated. The load applied to the pile head is checked by measuring the wire tension using a load-cell.

The sample is prepared in a $600 \mathrm{~mm} \times 600 \mathrm{~mm} \times$ $527 \mathrm{~mm}$ tank by pouring yellow Leighton Buzzard sand (Table 1) from a low drop height. This provides for a repeatable sample with a very low relative density of about $4 \%$. Such a density suppresses dilative effects that would be observed at higher relative densities. The pile, with properties given in Table 2, is fixed horizontally for installation and gently driven into the sand sample using a plastic hammer.

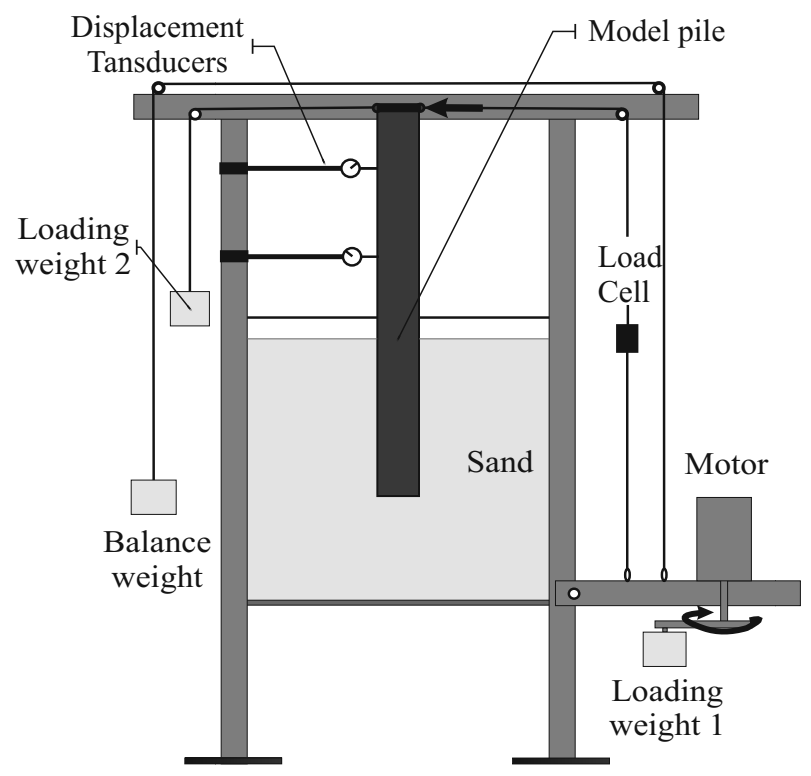

Figure 1. Lateral loading test equipment

Table 1.Properties of yellow Leighton Buzzard

\begin{tabular}{lll}
\hline Property & Description & Value \\
\hline$\gamma_{\max }\left(\mathrm{kN} / \mathrm{m}^{3}\right)$ & Maximum dry unit weight & 14.65 \\
$\gamma_{\min }\left(\mathrm{kN} / \mathrm{m}^{3}\right)$ & Minimum dry unit weight & 17.58 \\
$\mathrm{G}_{\mathrm{s}}$ & Specific grawity & 2.65 \\
$\varphi_{\mathrm{cr}}($ degrees $)$ & Critical angle of friction & 34.3 \\
$\mathrm{~d}_{50}(\mathrm{~mm})$ & Mean particle size & 0.80 \\
\hline
\end{tabular}

Table 2. Model pile properties

\begin{tabular}{lll}
\hline Property & Description & Value \\
\hline L $(\mathrm{m})$ & Pile embedded length & 0.36 \\
he $(\mathrm{m})$ & Load eccentricity & 0.43 \\
$\mathrm{D}(\mathrm{mm})$ & Pile diameter & 77 \\
$\mathrm{t}(\mathrm{mm})$ & Wall thickness & 2 \\
$\mathrm{E}(\mathrm{MPa})$ & Modulus of elasticity & 120 \\
\hline
\end{tabular}




\begin{tabular}{lccc}
\hline Test & Type & $\begin{array}{c}R_{d} \\
(\%)\end{array}$ & $\begin{array}{c}\text { Load series } \\
\left(N x \zeta_{\mathrm{b}}\right)\end{array}$ \\
\hline S1 & Static & $4 \%$ & - \\
\hline C1 & Cont. cyclic & $4 \%$ & $900 \times\left(\zeta_{\mathrm{b}}=0.29\right)$ \\
C2 & Cont. cyclic & $4 \%$ & $1300 \times\left(\zeta_{\mathrm{b}}=0.47\right)$ \\
C3 & Cont. cyclic & $4 \%$ & $300 \times\left(\zeta_{\mathrm{b}}=0.67\right)$ \\
\hline MA1 & Multi-amplitude & $4 \%$ & $900 \times \mathrm{C} 1-100 \times \mathrm{C} 2-1 \times \mathrm{C} 3-100 \times \mathrm{C} 2-$ \\
& cyclic & & $900 \times \mathrm{C} 1-100 \times \mathrm{C} 2-1 \times \mathrm{C} 3-100 \times \mathrm{C} 2-9,000 \times \mathrm{C} 1$ \\
MA2 & Multi-amplitude & $4 \%$ & $500 \times \mathrm{C} 0\left(\zeta_{\mathrm{b}}=0.27\right)-1 \times\left(\zeta_{\mathrm{b}}=0.31\right)-500 \times \mathrm{C} 0-1 \times\left(\zeta_{\mathrm{b}}=0.37\right)-$ \\
& cyclic & & $500 \times \mathrm{C} 0-1 \times\left(\zeta_{\mathrm{b}}=0.42\right)-500 \times \mathrm{C} 0-1 \times\left(\zeta_{\mathrm{b}}=0.46\right)-$ \\
& & $500 \times \mathrm{C} 0-1 \times\left(\zeta_{\mathrm{b}}=0.51\right)-500 \times \mathrm{C} 0-1 \times\left(\zeta_{\mathrm{b}}=0.58\right)-$ \\
& & & $500 \times \mathrm{C} 0-1 \times\left(\zeta_{\mathrm{b}}=0.60\right)-500 \times \mathrm{C} 0-1 \times\left(\zeta_{\mathrm{b}}=0.65\right)-6,000 \times \mathrm{C} 0$ \\
\hline
\end{tabular}

\subsection{Similitude framework for model testing}

Physical modelling using laboratory floor tests requires careful consideration of the scaling to ensure that the experimental outcome gives appropriate insight into full-scale behaviour. Accordingly the experimental tests have been designed using the dimensionless framework proposed by Leblanc et al. (2010a). This framework provides guidance for choosing appropriate pile dimensions and loading cases relevant to offshore wind turbine piles.

To supplement the work of Leblanc et al. (2010a) further consideration is given to the pile wall thickness and the pile bending stiffness. Figure 2 shows a plot of aspect ratio against pile relative stiffness, $K_{R}$, for a range of designs relevant to UK offshore wind farms (OWF). The selected wind farm sites are those of Barrow, Walney, London Array, Gunfleet Sands, Kentish Flats, Lynn and Inner Dowsing, Robin Rigg, Scroby Sands, Sheringham Shoal, North Hoyle, Burbo Bank and Rhyl Flat. The pile relative stiffness is calculated according to Poulos \& Hull (1989):

$$
K_{R}=\frac{E_{p} I_{p}}{E_{S L} \cdot L^{4}} \quad\left\{\begin{array}{cl}
>0.208 & \text { Rigid pile } \\
<0.0025 & \text { Slender pile }
\end{array}\right.
$$

In this Equation, $E_{p} I_{p}$ is the pile bending stiffness and $E_{S L}$ is the soil modulus at the pile tip, estimated using the small strain shear modulus. Shown on Figure 2 are boundaries defining rigid and flexible piles. Highlighted on this figure are three sets of data: (i) monopiles in sand, (ii) monopiles in clay and (iii) piles that were used in the 1960s and 1970s for the development of the current design guidelines $(p-y$ curves methods). This graph identifies the region where model piles should be located to capture field conditions, towards the top left corner. This is where the pile for the work described here is positioned.

\subsection{Test programme}

Table 3 describes the test program reported in this paper, showing a selection of static and continuous cyclic loading tests necessary for the interpretation of the results, and two multi-amplitude cyclic loading data. It is important to note that the cyclic tests described in Table 3 involve one-way loading where $M_{\text {min, }, y c l i c}=0$. A clear extension of the work is to incorporate two-way loading. In addition, the tests described here are unidirectional; there will of course be effects of direction. In Table 3, maximum load magnitude values are given as a fraction $\zeta_{\mathrm{b}}$ of the pile ultimate capacity $M_{R}(c f$. section 3.1$)$ :

$\zeta_{b}=\frac{M_{\max , \text { cyclic }}}{M_{R, \text { static }}}$

\section{EXPERIMENTAL RESULTS}

\subsection{Static and continuous cyclic tests}

First, the ultimate capacity of the pile was determined with the static test $\mathrm{S} 1$, in combination with

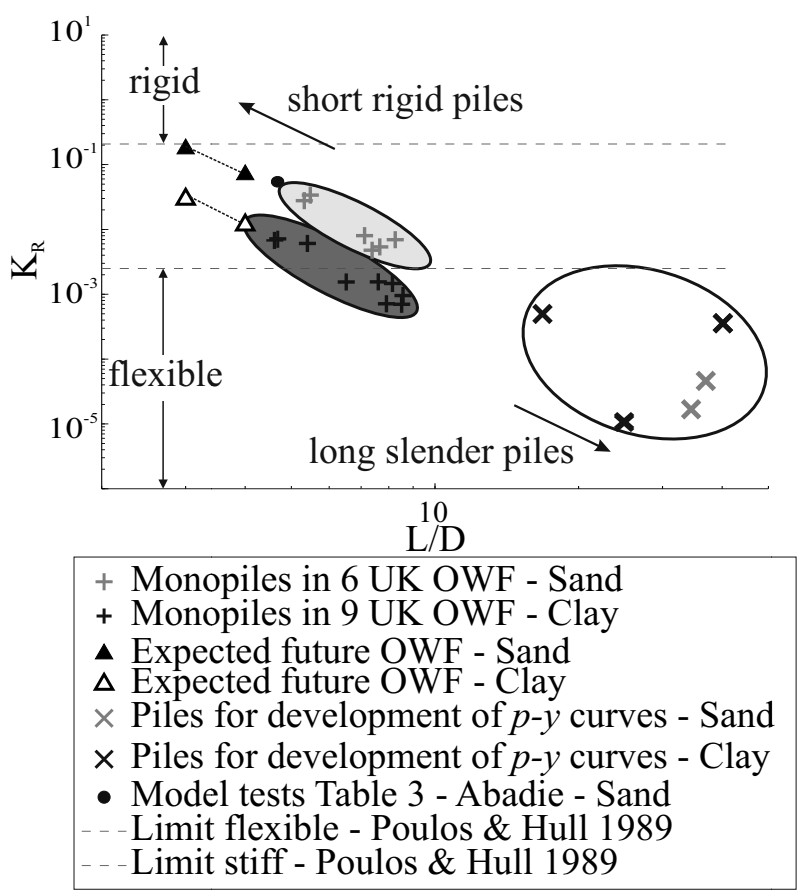

Figure 2. Pile relative stiffness vs. aspect ratio of piles relevant for the design of laboratory scale model tests 


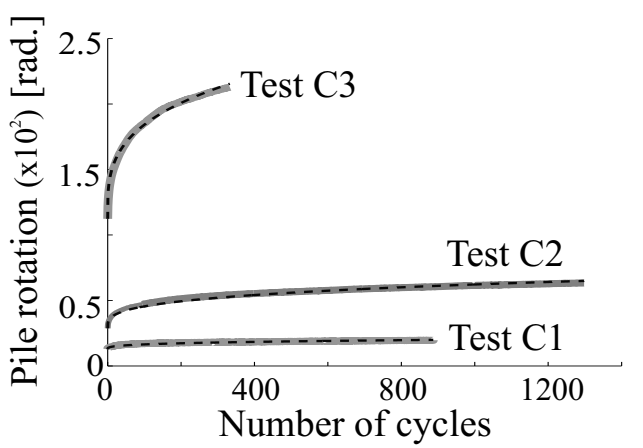

(a)

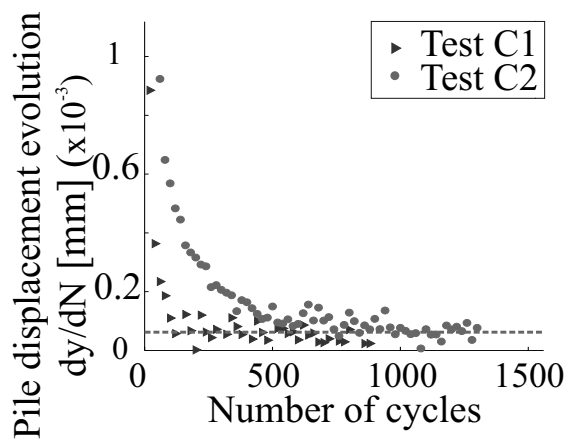

(b)

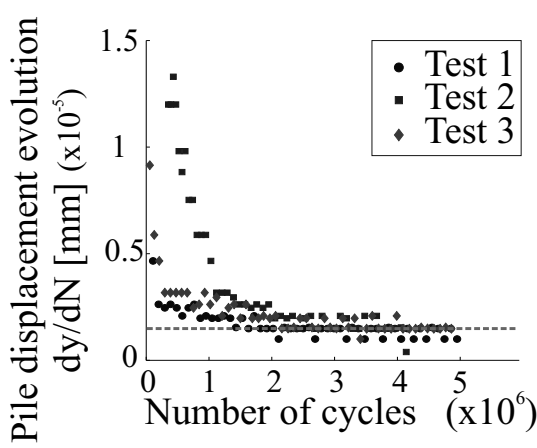

(c)

Figure 3. (a) Maximum pile rotation evolution during the cyclic loading test (continuous lines) and prediction using Equation (1) (dotted lines) (b) Measure of the pile displacement increase over cycles during tests C1 and C2 (c) Comparison with data published by Cuéllar (2011)

the method proposed in Abadie \& Byrne (2014). The value for $M_{R}$, equal to $31.1 \mathrm{Nm}$, is used as the reference load for the cyclic tests. The continuous cyclic test results $\mathrm{C} 1$ to $\mathrm{C} 3$ can be fitted according to Equation (1) and this is shown in Figure 3(a). The main feature of the test results from continuous cyclic loading is that the pile displacement increases with cycle number. Such behaviour is highlighted in Figure 3(b) where the rate of change in pile displacement $d y / d N$ reduces significantly in the first few cycles, before stabilising at a constant positive value.

Of course the number of cycles shown in these tests is around 1000, and so only a small fraction of the cyclic loading applied over the lifetime of a wind turbine pile. However the results are consistent with other testing (e.g. LeBlanc et al., 2010a) where more cycles were applied. The work also compares favourably to cyclic test data from Cuéllar (2011); the incremental pile displacements for these are shown in Figure 3(c). Cuéllar (2011) performed five laboratory floor model tests on rigid model piles, applying more than one million cycles. Three of the tests are displayed. Although the magnitude of the result is different the general trend appears to be similar.

\subsection{Multi-amplitude cyclic loading tests}

The multi-amplitude tests have been carefully chosen based on realistic design loads for ultimate (ULS), serviceability (SLS) and fatigue (FLS) limit states as described in Table 4 (from Leblanc et al., 2010a). The actual test sequences are described in Table 3. Test MA1 mimics the application of two storms on a continuous FLS cyclic load. Test MA2 has then been designed to better understand the influence of increasing load events on the pile response during continuous cyclic FLS loading. The moment-rotation curves for the two tests are shown in Figure 4. It is observed that for both tests the rotation tends to a limiting value once the pile has undergone the first series of storm type loads (e.g. $100 \mathrm{xC} 2-1 \mathrm{xC} 3-100 \mathrm{x}$ C2 for MA1 in Table 3).

This phenomenon is demonstrated on Figure 5(a) and 5(b) where the pile rotation is plotted against

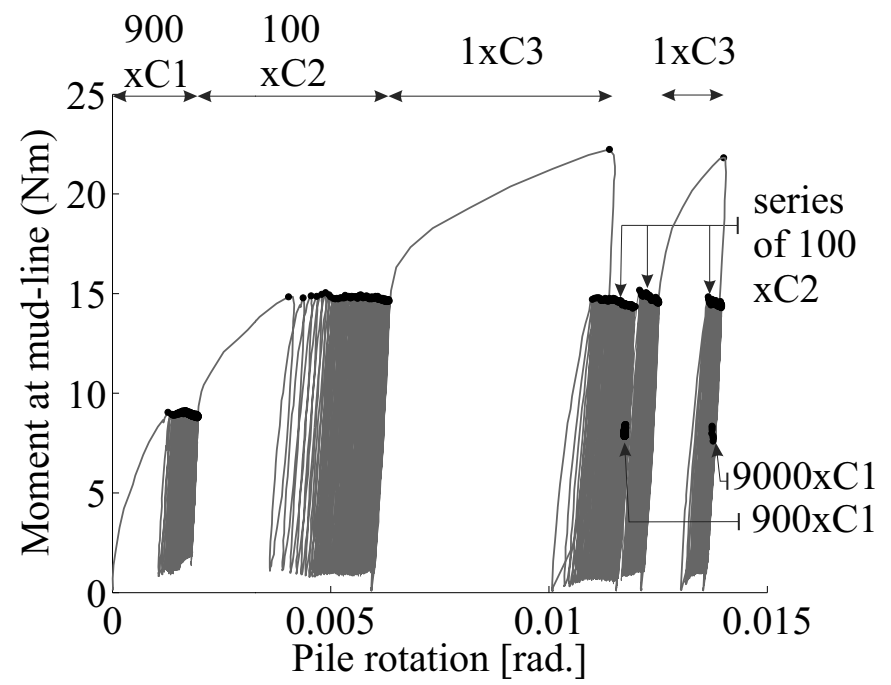

(a)

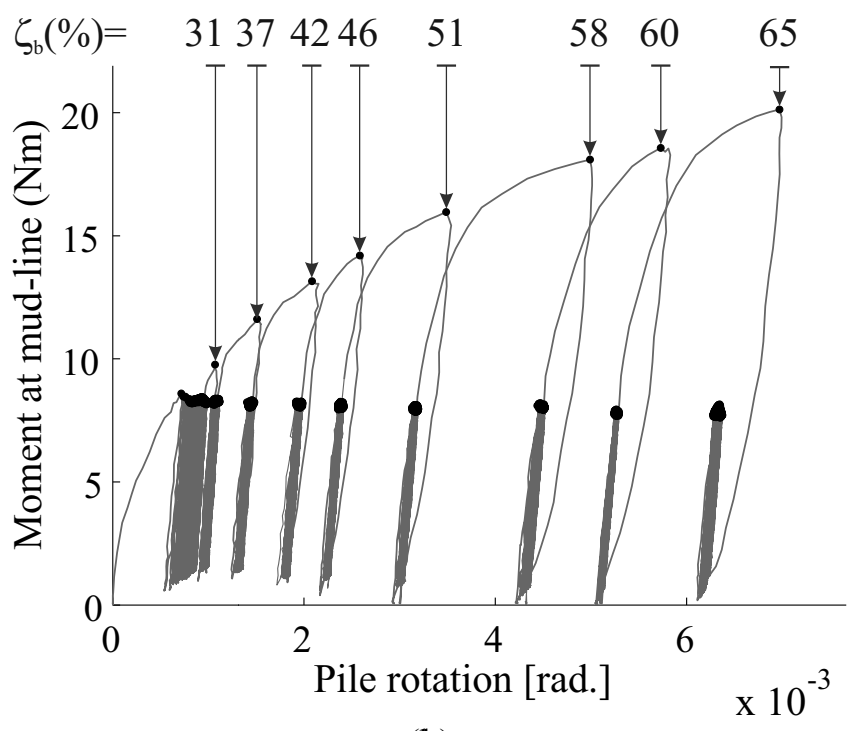

(b)

Figure 4. Results of the multi-amplitude cyclic test (a) MA1and (b) MA2: Moment-rotation response

Table 4. Relevant design loads for a $2 \mathrm{MW}$ turbine according to Leblanc et al. (2010a)

\begin{tabular}{lll}
\hline Load type & Relevant No. cycles & Load magnitude $\left(\zeta_{\mathrm{b}} \times M_{\mathrm{R}}\right)$ \\
\hline ULS & 1 & $0.74 \times \mathrm{xM}_{\mathrm{R}}$ \\
SLS & 100 & $0.47 \mathrm{xM}_{\mathrm{R}}$ \\
FLS & $10^{7}$ & $0.29 \mathrm{xM}_{\mathrm{R}}$ \\
\hline
\end{tabular}




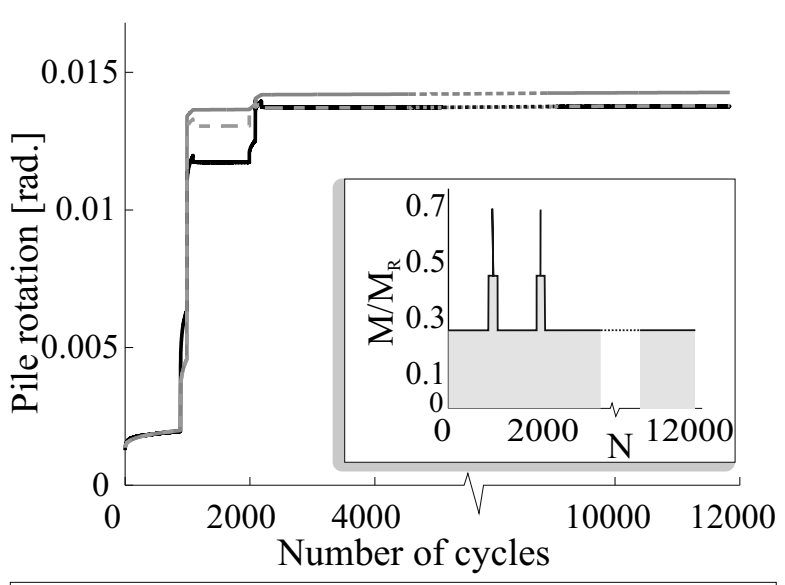

- Experimental results
- Prediction with linear conservative model
- - - Prediction with modified model (a)

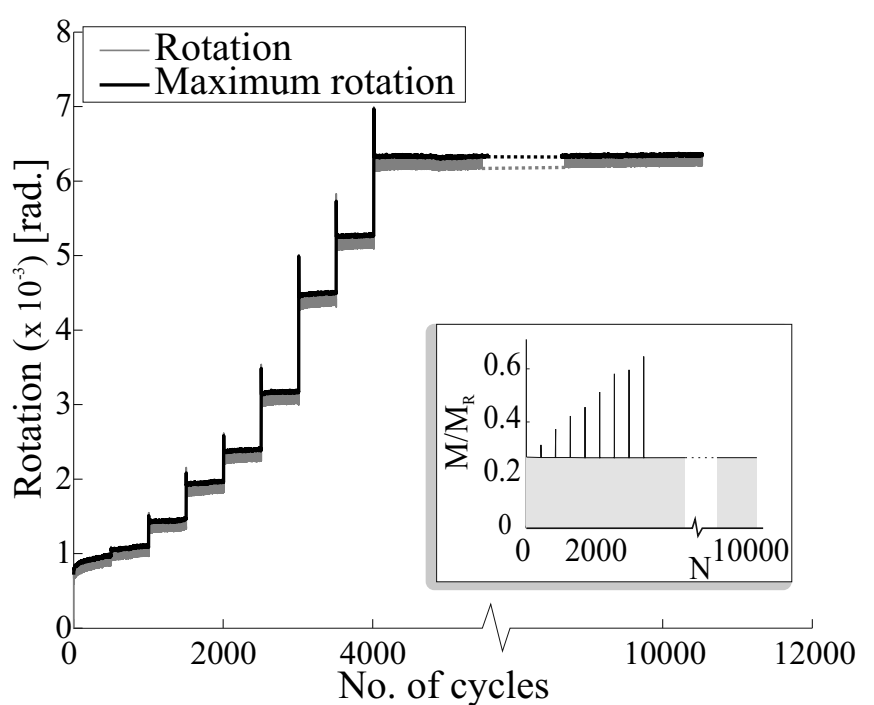

(b)

Figure 5. (a) Test MA1: maximum rotation evolution with number of cycles superimposed with predictions from the linear superposition model as proposed by Leblanc et al. (2010b) and modifications from Equation 8. (b) Test MA2: rotation evolution with number of cycles

cycle number for both tests. An interesting outcome of test MA2 is that the increase in rotation due to cyclic load amplitude $\mathrm{C} 0$ reduces to approximately zero following the fourth peak load event $\left(\zeta_{\mathrm{b}}=0.46\right.$, corresponding to a load magnitude of the SLS). Similar tests with larger cycle number would be helpful to assess the above statement for larger cycle numbers $\left(10^{7}\right)$, though it would require a higher cyclic frequency for tests to run in a reasonable time frame.

The two tests indicate that the pile displacement response, following a change in load, depends on whether there is an increase in load or decrease. Figure 6 demonstrates this by plotting the differences in pile head rotation against differences in load, when a change in load amplitude occurs. Decreases in load magnitude are displayed on the left, and increases on the right. It also shows that the order in which loads occur matters, by highlighting a sharper increase in pile rotation during the first storm events (top right ellipse) compared with the subsequent events (bottom right ellipse). The graph shows that there is significant non-linearity involved, corresponding to substantial plastic deformations occurring.

\section{METHOD FOR PREDICTION OF PILE ACCUMULATED ROTATION}

\subsection{Linear superposition model description}

The investigation of the relationship between spectrum loading and fatigue lifetime is important to accurately predict the evolution of pile deflection through random cyclic loading. First, the random loading history is decomposed into an equivalent set of uniform load reversals. This is a common procedure in fatigue life assessment and can be performed with extended rain-flow counting (Rychlik 1987). The decomposition of the load series enables a dam- age rule to be applied for predicting the fatigue lifetime. A common method is the linear cumulative damage rule, initially proposed by Palmgren (1924), and then popularised by Miner (1945). This concept was applied to laterally loaded piles by Lin \& Liao (1999), following the work of Stewart (1986). They demonstrated a good fit to their experimental results; however, their experiments only involved 50 cycles maximum. Extending this, Peralta (2010) performed tests of up to 45,000 cycles, finding that the method underestimated the final pile deflection. In contrast Leblanc et al. (2010b) found that such a method provided a good prediction to their test results.

The superposition method adopted here is described in detail by Leblanc et al. (2010b). If there are two load sequences subscripted $a$ and $b$, in the order $N_{a}$ then $N_{b}$, then firstly the accumulated rotation $\Delta \theta_{a}$ caused by $N_{a}$ cycles of lateral load $a$ is de-

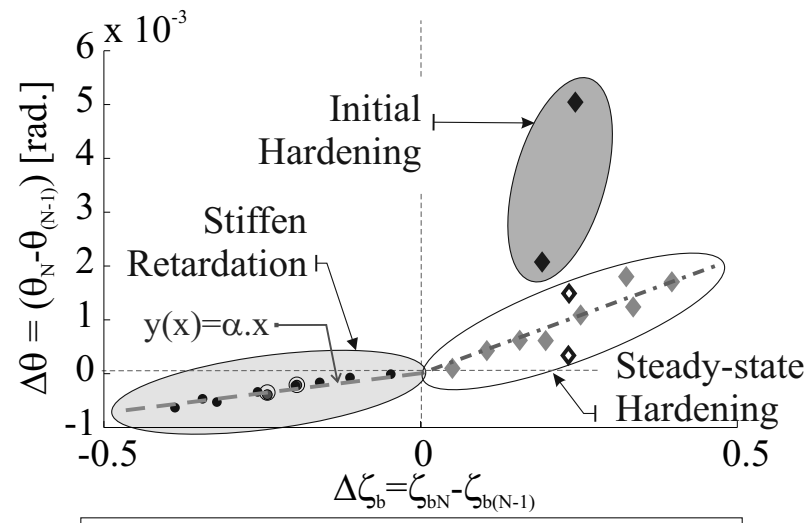

- Decreasing - Test MA1 first jump

- Decreasing - Test MA1 second jump

- Decreasing - Test MA2

- - Fitting curve

- Increasing - Test MA1 first jump

ه Increasing - Test MA1 second jump

Increasing - Test MA2

-..- Fitting Curve

Figure 6. Analysis of the change in rotation during the loading sequence changing phases 
termined using Equation (1):

$$
\Delta \theta_{a}=\left(T_{b} T_{c} \theta_{s}\right)_{a} \cdot\left(N_{a}\right)^{0.31}
$$

This can be made equivalent to $N_{a b}^{e q}$ cycles of load type $b$ using the calculation:

$$
N_{a b}^{e q}=\left(\frac{\Delta \theta_{a}}{\left(T_{b} T_{c} \theta_{s}\right)_{b}}\right)^{0.31}
$$

If $N_{b}$ cycles of load $b$ are then applied to the pile, the overall accumulated rotation is given by:

$$
\Delta \theta_{\text {tot }}=\left(T_{b} T_{c} \theta_{s}\right)_{b} \cdot\left(N_{b}+N_{a b}^{e q}\right)^{0.31}
$$

The total pile rotation is then calculated as:

$\theta_{b}=\Delta \theta_{t o t}+\max \left\{\theta_{0, a}, \theta_{0, b}\right\}$

\subsection{Modification based on experimental results}

Tests $\mathrm{C} 1$ to $\mathrm{C} 3$ make it possible to deduce the corresponding values of $T_{b}, T_{c}$ and $\theta_{s}$ for each load type applied in the multi-amplitude tests. The above linear superposition method is applied to test MA1 with the results shown in Figure 5(a). The model broadly captures the results, slightly over-predicting the final pile rotation but with an acceptable error of $3.7 \%$. We propose modifying the calculation, taking account of observations from Figure 6 for decreases in load, by changing the term $\max \left\{\theta_{0, \mathrm{a}}, \theta_{0, \mathrm{~b}}\right\}$ in Equation (7) to:

$$
\Theta_{t h}=\left\{\begin{array}{cc}
\max \left\{\theta_{0, a}, \theta_{0, b}\right\} & \text { if } \Delta \zeta_{b}>0 \\
\max \left\{\theta_{0, a}, \theta_{0, b}\right\}+\alpha \Delta \zeta_{b} & f \Delta \zeta_{b}<0
\end{array}\right.
$$

In this Equation, $\alpha$ is the slope of the fitting law for descending load sequences. The results of such a calculation are given in Figure 5(a), showing a better prediction of the final rotation (error of $0.16 \%$ ). Additional work is needed to develop a better understanding of the term $\Theta_{\text {th. }}$. New methods must capture the non-linearity of pile response more accurately, recognising that the cyclic accumulated pile loaddisplacement response is unlikely to be calculated precisely using linear superposition methods.

\section{CONCLUSION}

This paper presents a series of laboratory floor model tests exploring pile response under multi amplitude cyclic loading, representing storm loading on the pile. An important observation from this work is that the pile rotation appears to reach a limiting value following a series of maximum storm type loads. The paper shows that the pile response to multi amplitude cyclic loading involves significant nonlinearity, particularly when large plastic defor- mations occur. A linear superposition method, such as described by Leblanc et al. (2010b), is shown to provide a reasonable but conservative approximation to the final pile rotation. This is modified to predict the pile response more accurately.

To further develop these methods research must focus on understanding the non-linearity highlighted in section 3.2, for both loading and unloading. Targeted laboratory floor testing and field testing, along with theoretical development, will be needed. The resulting model would improve design guidance for cyclic loading of offshore wind turbine monopiles.

\section{ACKNOWLEDGEMENTS}

The first author thanks the generous support from EDF R\&D and EDF Energies Nouvelles.

\section{REFERENCES}

Abadie, C. N. \& Byrne, B.W. (2014). Cyclic loading response of monopile foundations in cohesionless soils. International Conference of Physical Modelling in Geotechnics (ICPMG). Perth, Australia. pp. 779-784.

Cuéllar, P. (2011). Pile Foundations for Offshore Wind Turbines: Numerical and Experimental Investigations on the Behaviour under Short-Term and Long-Term Cyclic Loading. $\mathrm{Ph}$. D. thesis, BAM, Bundesanstalt fr Materialforschung undprfung, Berlin.

Dietrich, T. (1982). Incremental parabolic hardening of psammic material; application to laterally-loaded piles. IUATAM Conference on Deformation and Failure of Granular Materials, Delft, pp. 13-22.

Klinkvort, R. T. (2012). Centrifuge modelling of drained lateral pile-soil response. $\mathrm{Ph}$. D. thesis, DTU.

Leblanc, C., G. T. Houlsby, \& B. W. Byrne (2010a). Response of stiff piles in sand to long-term cyclic lateral loading. Géotechnique 2, 79-90.

Leblanc, C., B. W. Byrne, \& G. T. Houlsby (2010b). Response of stiff piles to random two-way lateral loading. Géotechnique 9, 715-721.

Lin, S.-S. \& J.-C. Liao (1999). Permanent strains of piles in sand due to cyclic lateral loads. Journal of Geotechnical and Geoenvironmental Engineering 125, 798-802.

Miner, M. A. (1945, September). Cumulative damage in fatigue. journal of applied mechanics, 159-165.

Palmgren, A. G. (1924). Die lebensdauer von kugellagern (life length of roller bearings, in german). Zeitschrift des Vereines Deutscher Ingenieure (VDI Zeitschrift), ISSN 68, No.14, 339-341.

Peralta, P. (2010). Investigations on the Behavior of Large Diameter Piles under Long-Term Lateral Cyclic Loading in Cohesionless Soil. Ph. D. thesis, University of Hannover

Poulos, H. G. \& T. S. Hull (1989). The role of analytical mechanics in foundation engineering. Foundation Engineering, Current Principals and Practices, ASCE 2, 1578-1606.

Rovere, M. (2004). Cyclic loading test machine for caisson suction foundations. Master's thesis, Centrale Lille and Politechnico di Milano.

Rychlik, I. (1987). A new definition of the rainflow cycle counting method. Int. J. Fatigue 9, 119-121.

Stewart, H. E. (1986). Permanent strains from cyclic variable amplitude loadings. J. of Geotechnical Engineering, ASCE 112, No.6, 646-660. 